\title{
Practical Elements of Mechanical Engineering - An Enrichment to University Engineering Education
}

\author{
Anthony G. Straatman \\ Department of Mechanical \& Materials Engineering \\ Western University, London, Canada N6A 5B9 \\ astraatman@eng.uwo.ca
}

\begin{abstract}
Practical Elements of Mechanical Engineering (PEME) is an enrichment program developed by the Department of Mechanical and Materials Engineering at Western University in collaboration with Fanshawe College of Applied Arts and Technology. The PEME program was developed mainly in response to the changing backgrounds of students entering university engineering programs, and to provide an opportunity for students to get exposure to practical courses in machining, welding, metrology, and other practical areas, which complement the traditional Mechanical engineering curriculum. The PEME program is thus a formal avenue whereby students have an opportunity to gain some additional practical knowledge of their profession.
\end{abstract}

Keywords: Engineering externship, practical elements, enrichment.

\section{INTRODUCTION}

The background of a typical student entering a university program in engineering has changed dramatically over the past 20-30 years. The simplest things, like knowing the names of various tools and machines has essentially become a lost skill for much of the incoming cohort. While decades ago, students were often attracted to engineering by their experiences with fixing things, or taking things apart, or taking technical courses in high school, this is no longer the norm. Our current in-coming students come from a virtual world where playtime, laboratory and physical demonstrations have been replaced by video games, internet gadgets and Youtube $^{\mathrm{TM}}$ videos. Add to this that the high school curriculum in Ontario was condensed from 5 to 4 years in 2003-04, and that many high schools have reduced or eliminated technical shop programs due to the high cost of equipment and continuing challenges with health and safety. All this adds up to radical and continuing change in the backgrounds of incoming engineering students.
The PEME program was developed to give students an opportunity to enrich/complement their university engineering education by taking courses that focus on the "practical elements" of the discipline. More than simply showing students a machine or series of machines, the PEME program gives students hands-on practice with machines and measurement tools in an intensive program that covers practical elements in sufficient detail to give the students a true appreciation of them. While courses at the university are lecture-heavy (typically 3:1 lecture to lab/tutorial), the courses in the PEME program are mostly the opposite with many courses having one lecture hour followed by 2-3 laboratory hours.

The PEME program is comprised of two academic terms at Fanshawe College, the first of which has 8 introductory courses, and the second, 6 advanced courses in engineering practice. In this respect, electing to take the full PEME program is not a small endeavor; it is a significant commitment that must be made on full-time basis over 2 consecutive summer terms, or during a regular academic year, while deferring their university studies by one year. The program has now been offered to undergraduates in Mechanical \& Materials engineering since 2010 and has graduated numerous students.

This paper presents details of the program structure, the courses offered, and the delivery approach, followed by student comments and testimonials and data from graduated students.

\section{THE PEME PROGRAM}

\subsection{Semesters and Courses}

The program is comprised of 2 academic semesters and is delivered at Fanshawe College of Applied Arts and Technology. The program is formally split into PEM1 and PEM2 at the college, with both PEM1 and PEM2 offered all three semesters (fall, winter, summer) of the year. Figure 1 shows the course numbers/names and the semester credits associated with each course. 
Semester 1

CADD-1054

CADD-1055

$\mathrm{MACH}-1124$

WELD-1040

METH-1002

ENGR-1020

$\mathrm{MECH}-1072$

MATS-1021

\begin{tabular}{ll} 
& Credits \\
\cline { 2 - 2 } ENG DWG \& BPR & 2.00 \\
CADD Fundamentals & 1.50 \\
Machining 1 & 2.00 \\
Welding Technology 1 & 2.00 \\
Technology in Industry & 3.00 \\
ENG-Design 1 & 3.50 \\
SPC \& Metrology & 3.00 \\
Ferrous Metallurgy & 2.00
\end{tabular}

Total semester credits 19.00

Nominally $\underline{28}$ hours per wk.

Semester 2
WELD-1047
MACH-1144
MECH-1090
MECH-3034
MGMT-1007
MECH-3035

\begin{tabular}{ll} 
& Credits \\
\cline { 2 - 2 } Production Welding & 3.00 \\
CNC Machining & 3.50 \\
Tool Design I & 1.00 \\
HYD/PNEU/PLC & 4.00 \\
Project Management & 3.00 \\
Practical Project & 2.00
\end{tabular}

Total semester credits 16.50

Nominally $\underline{23}$ hours per wk.

Fig. 1. Curriculum chart for PEM1 and PEM2

The first semester is comprised of courses that provide a foundation of basic practical skills. MACH-1124, WELD-1040 and MECH-1004 provide basic instruction in hand machining operations, hand welding and measurement technology; CADD-1054 and CADD-1055 extend the student's knowledge of Computer aided design and, more importantly, the art of CADD communication through working drawings. METH-1002 and MATS1008 provide insight into methods and processes for production of materials and components. More detailed descriptions of the courses are available at the Fanshawe College website [1], or via the Western Engineering website [2].

When one looks at the courses in detail, the most salient common feature is the ratio of laboratory time to classroom time. Consider, for example MACH-1124 and WELD-1040, where students spend 1 hour in the classroom for every 2-3 hours in the lab. This is one intentional feature of PEME and, with the exception of few courses, is the model for the entire curriculum. The emphasis on practice and hands-on distinguishes this training from the fundamental training that forms the main basis of their University Engineering education. The courses in PEME have been designed specifically to give the students insight into the various machines, tools (including hand and computing), measurement devices and techniques, and processes. Such training gives a working knowledge into what a particular machine is capable of, the setup and time associated with various operations, and an appreciation for how difficult it can be to carry out an operation to a tight tolerance.

The CADD-1054 course in Engineering drawing and Blueprint Reading takes CADD training to a higher level than what is expected in the University program, but also focuses on engineering communication by in-depth study of working drawings and shop-floor drawings, a skill that is greatly appreciated by student and employer when entering the engineering workforce. Further, CADD1055 is an opportunity to introduce computer aided design at a more in-depth level, and to introduce software that is not used in the University Engineering program.

In semester 2, the focus turns to more sophisticated levels of machining and welding, with the addition of tool design, an introduction to hydraulic and pneumatic control (MECH-3023), and tool design. Among the favorite courses in the program is the final project course, $\mathrm{MECH}-$ 3035, which has students manufacture a project of their design. Projects have ranged in complexity from gas barbeques to rocket engines and everything between.

\subsection{Delivery Model}

The original delivery of the program was during the normal academic year of the College (September-April). The students enrolled in the PEME program, took PEM1 in the fall semester, and then moved directly to PEM2 in the winter semester without having to re-register; i.e. PEME meant taking both semesters. While the students were enrolled in PEME, they were enrolled in an externship course at Western called ES 2274 Engineering Externship. In this manner, PEME students were full-time students at the College and remained students at Western, with privileges to use the library facilities, etc.

A recent change to the program has split PEME distinctly into two parts, PEM1 and PEM2, with no requirement that students must take both; the only caveat is that PEM1 is a prerequisite for PEM2. The change was made specifically to make PEME more accessible to students who did not wish to take an additional full year to complete their engineering studies at Western. Under the new delivery model, students who complete PEM1-only receive an Ontario College Local Certificate from Fanshawe College and credit (SAT) for ES 2274 Engineering Externship I at Western university. Students who complete both PEM1 and PEM2 receive an Ontario College Graduate Diploma from Fanshawe College and 
credit for ES 2274 - Engineering Externship I and ES 2275 - Engineering Externship II at Western university.

The new delivery model also enables more freedom in its delivery at the College. Fanshawe College currently offers both PEM1 and PEM2 in all semesters, including the summer. In this manner, students can elect to take PEME during the summer months and not extend their engineering program. In addition, students can combine the PEME program with other opportunities like summer co-op, industry internship, combined or dual degrees, etc.

While originally the notion of having to spend an additional year (or semester) may have dissuaded students from enrolling in PEME, it is much more common today for students to enrich their engineering degree; taking an additional year to complete their engineering studies is generally not an issue as students appreciate the opportunities to take dual/combined/concurrent degrees, co-op semesters, internship placements and PEME.

\section{STUDENT TESTIMONIALS}

PEME was offered for the first time in September of 2010, wherein 13 students from Mechanical \& Materials engineering enrolled. It has now been offered 4 times during the normal academic year (September - April) and once during the summer (PEM1 only). Forty-five (45) Western engineering students (and numerous foreign students) have now taken the program, with several more enrolled for summer 2015. Several student comments are provided below (names are abbreviated to initials):

PG, PEME 2011-12, currently employed at automotive OEM:

Taking part in the Practical Elements of Mechanical Engineering program is the best choice I have made since making the decision to attend Western University. The comprehensive courses have provided me with practical knowledge that has, and will continue to, give me the competitive edge in my university studies and professional career.

I have a strong belief that the PEME program was a big contributor to me getting and excelling at my position immediately after graduation. My position as a Powertrain Cooling engineer for a major automotive OEM requires me to design and validate the production of engine cooling components with a number of criteria in mind. Performance, manufacturability, serviceability, cost, weight, among many other factors need to be considered when designing each individual component. The skills taught in the PEME program provided me with a base of practical knowledge that I could leverage in my understanding of the systems and processes involved in developing, validating, and producing a best in class product line-up.

One of the most important skills I developed while completing the PEME program was a better understanding and appreciation for the skilled trades. Thanks to the PEME program I now have the base skills and understanding required to go onto the shop floor and have a productive conversation with a tradesman. Being able to leverage their years of experience and combine it with the theoretical knowledge I obtained at UWO has allowed me to effectively develop parts, which better suit our needs, with fewer revisions. The ability to communicate effectively with our manufacturing team immediately upon hire has allowed me to accelerate my working relationship with them to a point which takes many engineers (without extensive practical knowledge) years to develop.

I would like to re-iterate that I believe the PEME program has been a significant contributing factor to my early success in my manufacturing career. I strongly recommend the program to any engineering student planning to enter a career environment which is heavy in manufacturing. The skills and principles taught will prove invaluable for effectively executing your position and building working relationships.

KO, PEME 2011-12, currently in MME yr. 4: The PEME program is an excellent opportunity to build upon what you learn at Western. The practical aspect really helped me gain a better understanding of the theory I had already learned. Also now being back at Western, I can better grasp the theory I'm learning based on my practical experience gained at Fanshawe. I strongly recommend participating in the program, especially if you prefer a hands-on or practical application type learning style.

JF, PEME 2011-12, currently employed at automotive OEM:

After finishing the PEME program I am much more conscious of manufacturing capabilities, component availability, and product assembly during the engineering design process. I now have the confidence to describe to a potential employer how a product can be designed as well as manufactured effectively.

VM, PEME 2011-12, currently employed at automotive OEM:

Practical Elements in Mechanical Engineering offer students the opportunity to develop hands-on skills, 
designed to augment the foundational knowledge established through Western Engineering's curriculum. This serves to strengthen student's technical analysis capabilities, allowing for greater understanding, and working knowledge, of modern processes employed today by many of the world's leading manufacturers.

TB, PEME 2011-12, currently in MME yr. 4: I enjoyed learning how to use multiple tools and machines on a daily basis at Fanshawe. The professors were very knowledgeable and helpful. The following summer I got my first engineering related job because of the practical experiences I learnt.

JT, PEME 2011-12, currently in MME yr. 4: After completing the PEME program, I feel like I now have a better fundamental understanding of various manufacturing design processes that will benefit me as a new graduate in industry.

AK, PEME 2010-11, currently employed at automotive OEM:

Throughout this year I have seen myself grow as an engineer. The amount of useful information and skills we have developed will greatly help us in our future careers.

CD, PEME 2010-11, currently employed: This program has reduced the learning curve once I get into a full-time engineering position. The program gave me a better feel for what I could be doing in industry because of the teacher's personal experiences and how that came through in their classes

\section{THE MESSAGE FROM INDUSTRY}

As PEME was developed with industry in mind, and with the assistance of several industry employers, the uptake of students has been excellent. Employers are asking specifically for students with experience, whether that be in the form of a co-op experience, work with a project team like Formula SAE, or PEME. The advantage that PEME has over other experiential learning opportunities is that the program is absolutely objective. While a co-op job may be an excellent learning experience, many are not; similarly, work with a project team may not necessarily involve practice. Taking the PEME program ensures that every student has practice in machining, welding, measurement, CAD and Blueprint reading, and all of the other practical elements taught. In this manner, PEME is a very prescriptive experiential learning model that ensures that all students will have a similar understanding of practice. This makes graduates of the program very attractive to industry.

\section{SUMMARY}

Practical Elements of Mechanical Engineering (PEME) has been developed by Western University's Mechanical \& Materials Engineering department and Fanshawe College of Applied Arts and Technology. PEME was developed as an enrichment program for students wishing to enhance their university engineering education with one or two semesters of practical engineering skills more typically offered to Technicians/Technologists in community college programs. The PEME program delivers courses in machining, welding, metrology, CADD, and other practical skills to give engineering students an appreciation of different operations, an understanding of the capabilities and limitations of machines, and a better understanding of engineering communication via blueprint reading, tolerance specification and CADD. The program has now been offered for 4 years at Fanshawe College and has received excellent feedback from students and industry alike. One key advantage over co-op and industry internship is that the program is prescriptive and, therefore, ensures that every graduating student has had the same exposure to all of the practical elements.

\section{Acknowledgements}

The author wishes to acknowledge Dr. John Makaran who contributed heavily to the original development of the program. The author also wishes to acknowledge Fred Varkaras and Ian Neves, each of whom served as coordinators for the program, and Vertha Cologan, the current Dean of the Faculty of Technology at Fanshawe College. Finally, the author wishes to acknowledge Dan Smith, the current coordinator of the PEME program. All their efforts have ensured that the program continues to be delivered with extremely high quality.

\section{References}

[1] http://www.fanshawec.ca/programs-courses/full-timeprograms/pem1/20156/courses

[2]http://www.eng.uwo.ca/mechanical/undergraduate/peme/ind ex.html 